\title{
High Rate of Ceramic Sandwich Liner Fracture
}

\author{
Ronny Lopes MD, Jean M. Philippeau MD, \\ Norbert Passuti MD, PhD, François Gouin MD, PhD
}

Received: 21 June 2011 / Accepted: 31 January 2012 / Published online: 2 March 2012

(C) The Association of Bone and Joint Surgeons (B) 2012

\begin{abstract}
Background Ceramic bearing surfaces for THA were introduced to reduce the risk of wear. However, owing to liner fracture in some of the early series and presumption that the fractures were the result of the modulus mismatch of the implant and the bone, a ceramic sandwich liner with lower structural rigidity was introduced. Fractures of these devices also were reported subsequently, although the incidence is unclear and it is unknown whether there are any risk factors associated with the fractures.

Questions/purposes We therefore determined the incidence of these fractures.

Each author certifies that he or she, or a member of their immediate family, has no commercial associations (eg, consultancies, stock ownership, equity interest, patent/licensing arrangements, etc) that might pose a conflict of interest in connection with the submitted article.

Clinical Orthopaedics and Related Research neither advocates nor endorses the use of any treatment, drug or device. Readers are encouraged to always seek additional information, including FDA-approval status, of any drug or device prior to clinical use. All ICMJE Conflict of Interest Forms for authors and Clinical Orthopaedics and Related Research editors and board members are on file with the publication and can be viewed on request.

Each author certifies that his or her institution waived approval for the reporting of this case and that all investigations were conducted in conformity with ethical principles of research.
\end{abstract}

R. Lopes, J. M. Philippeau, N. Passuti, F. Gouin

Department of Orthopaedic Surgery, Hotel Dieu Hospital,

Rue Gaston-Viel, 44000 Nantes, France

N. Passuti, F. Gouin ( $\square)$

Bone Resorption and Primitive Bone Tumor Physiopathology

Research Laboratory, INSERM U957, School of Medicine,

Nantes University, Nantes, France

e-mail: fgouin@chu-nantes.fr; francois.gouin@chu-nantes.fr
Methods We retrospectively reviewed 298 active patients in whom we implanted 353 ceramic-polyethylene sandwich liner acetabular components between November 1999 and February 2008. The mean age of the patients was 53.6 years (range, 17-84 years). The minimum followup was 6 months (mean, 41 months; range, 6-106 months). All patients were assessed clinically and radiographically. Results Seven of the $353(2 \%)$ ceramic sandwich liners fractured at a mean of 4.3 years (range, 1.3-7.6 years) after surgery without trauma. Neither patient-related factors nor radiographic position of the implants were risk factors for fracture.

Conclusions Owing to the high rate of fractures of the sandwich ceramic polyethylene liners in our patients, we have discontinued use of this device.

Level of Evidence Level IV, therapeutic study. See Guidelines for Authors for a complete description of levels of evidence.

\section{Introduction}

Owing to low wear, an alumina-alumina bearing surface for THA is an attractive alternative to other traditional bearing surfaces, especially for young people. Boutin [3, 4] developed and implanted the first alumina-ceramic implant in 1970. It has been in use for more than 40 years with survival rates ranging from $100 \%$ at 11 years [11] to $84.4 \%$ after 20 years [14]. One study [1] reported a $0.01 \%$ incidence of fracture. Fractures were presumed to be the result of fatigue failure, possibly exacerbated by manufacturing defects in the material.

Since the introduction of ceramics 40 years ago, manufacturing technology has evolved and improved. To reduce the modulus mismatch, a new design of liner consisting of a 
layer of polyethylene layered between the metallic cup and a layer of alumina was introduced in 1993. This retained the ceramic-ceramic bearing surface but produced an implant of much lower structural stiffness. Ravasi and Sansone [17] reported preliminary clinical findings for 53 patients at a mean followup of 7 months. They reported the short-term "results are positive and encouraging". Hasegawa et al. [9] reported a specific type of fracture associated with this device: a ceramic sandwich liner fracture. Others $[8,12,15$, 16] also reported such fractures. However, the incidence of these fractures is unclear and it is not known whether there are any specific risk factors for these fractures.

We therefore (1) determined the incidence of these fractures; (2) describe all the cases, and (3) compared clinical and radiographic results between the nonfracture and fracture groups.

\section{Patients and Methods}

We retrospectively reviewed 298 patients who had 353 Alpha CERASUL ${ }^{\mathrm{TM}}$ (Zimmer, Winterthur, Switzerland) sandwich liner acetabular components implanted between November 1999 and February 2008. This implant consisted of a layer of polyethylene between the titanium alloy cup and a layer of alumina (hot isostatically pressed aluminum oxide) for conserving the ceramic-ceramic bearing surface. All patients during this period received this implant unless the shell required was smaller than $50 \mathrm{~mm}$ : we implant the CERASUL $^{\mathrm{TM}}$ liner only for shells larger than $50-\mathrm{mm}$ diameter to conserve a thickness of $8 \mathrm{~mm}$ of UHMWPE. We had no contraindication for use of the implant. During that same time, we treated a total of 306 patients with THA. Of the remaining 298 patients ( 353 hips), nine died (nine hips) during the study period from unrelated causes after hip arthroplasty. Another six patients (six hips) were lost to followup. Information for 14 patients (15 hips) who were unable to attend our outpatient clinic was gathered through telephone interviews. There were 183 males and 115 females with a mean age at the time of arthroplasty of 53.6 years (range, $17-84$ years). The right hip was replaced in $192(54 \%)$ patients and the left hip in $161(46 \%)$ patients. Before THA, 70 hips (19.5\%) had surgical antecedents. Of the 298 patients, 215 had a minimum followup of 2 years (mean, 3.5 years; range, 0.5-8.8 years). We included all patients for reporting of complications.

The main preoperative diagnosis was osteonecrosis (Table 1). The average preoperative Merle d'Aubigné-Postel score [6] was 10.9 (range, 1-18). According to the Charnley score [5], 135 patients $(45 \%)$ were classified as A, $63(21 \%)$ as B, and $100(34 \%)$ as C. On average, the patients were slightly overweight with a mean BMI of $26.4 \mathrm{~kg} / \mathrm{m}^{2}$ (range, $17.2-42.5 \mathrm{~kg} / \mathrm{m}^{2}$ ).
Table 1. Preoperative diagnoses

\begin{tabular}{lcc}
\hline Diagnoses & $\begin{array}{l}\text { Number } \\
\text { of hips }\end{array}$ & $\%$ \\
\hline Primary coxarthrosis & 127 & $37 \%$ \\
Osteonecrosis & 97 & $28 \%$ \\
Coxofemoral dysplasia & 53 & $15 \%$ \\
Revision surgery & 28 & $8 \%$ \\
Trauma & 17 & $5 \%$ \\
Other & 13 & $4 \%$ \\
Inflammatory disease & 11 & $3 \%$ \\
Posttraumatic coxarthrosis & 7 & $2 \%$ \\
\hline
\end{tabular}

Surgery was performed by one of 10 surgeons using the same procedure in a conventional operating room specifically used for orthopaedic surgery. The surgery was performed with the patients under general anesthesia and using a posterolateral approach, except in five patients (1\%) who were operated on through an anterolateral approach. The femoral stems were cementless in 306 hips $(87 \%)$ (Orphee ${ }^{\circledR}$ or Avenir ${ }^{\circledR}$; Zimmer, Winterthur, Switzerland) and cemented in 34 hips $(10 \%)\left(\mathrm{PF}^{\mathbb{R}} ;\right.$ Zimmer $)$, and not changed for 12 revisions (3\%). All bearing surfaces were alumina-on-alumina with a CERASUL ${ }^{\mathrm{TM}}$ Alpha sandwich ceramic liner and an alumina (third-generation) CERASUL ${ }^{\mathrm{TM}}$ femoral head ( $28 \mathrm{~mm}$ in all cases). The acetabular cup was always cementless and was made of titanium, Allofit ${ }^{\mathbb{R}}$, or Pressfit $^{\mathbb{R}}$ (Zimmer). The minimal acetabular shell size for the use of this sandwich ceramic liner was $52 \mathrm{~mm}$. The CERASUL $^{\mathrm{TM}}$ Alpha components consisted of a modular socket with a thin 4-mm layer of third-generation ceramic bloc $\left(\right.$ BIOLOX $^{\circledR}$ forte; CeramTec AG, Plochingen, Germany) that had been assembled using a thermocompressive technique that made a variable-thickness polyethylene shell. The bloc was used in a range from a $52-\mathrm{mm}$ to $68-\mathrm{mm}$ diameter polyethylene shell with an apical spike and four peripheral notches. The sandwich ceramic liner was housed in an acetabular cup using snap-fit fixation.

All patients received intravenous antibiotic prophylaxis perioperatively and were given heparin as thromboembolism prophylaxis. Patients were mobilized on the first postoperative day and were encouraged to walk with partial weightbearing on the second postoperative day with full weightbearing after 1 month.

Clinical and radiographic evaluations were performed at 6 weeks, 3 and 6 months, and 1 year after surgery, and then annually thereafter. Each patient was assessed preoperatively and at the last followup. Patients were classified according to the activity scores described by Charnley [5] and Devane et al. [7]. Hip function was evaluated with the score reported by Merle d'Aubigné and Postel [6].

AP radiographs of the pelvis and AP and lateral radiographs of the hip were made from a standard distance with 
the patient in a standard position. One observer (HR) not involved in the treatment evaluated all radiographs. Abduction of the acetabular component was evaluated on the pelvic radiograph by the angle formed tangentially between the acetabular component lines with the teardrop radiographic lines or tangent to the inferior part of the ischial tuberosities line.

\section{Results}

Seven fractures $(2 \%)$ were detected and revised in the sandwich ceramic liners (Fig. 1). The average time between surgery and fracture diagnosis was 51 months (range, 15-91 months). The ceramic sandwich liner fractures occurred in six men and one woman who had a mean age of 48.4 years (range, 38-55 years), a mean weight of $75.8 \mathrm{~kg}$ (range, $56-125 \mathrm{~kg}$ ), and a mean BMI of $24.5 \mathrm{~kg} / \mathrm{m}^{2}$ (range, $20-38.6 \mathrm{~kg} / \mathrm{m}^{2}$ ). Three of these seven patients had
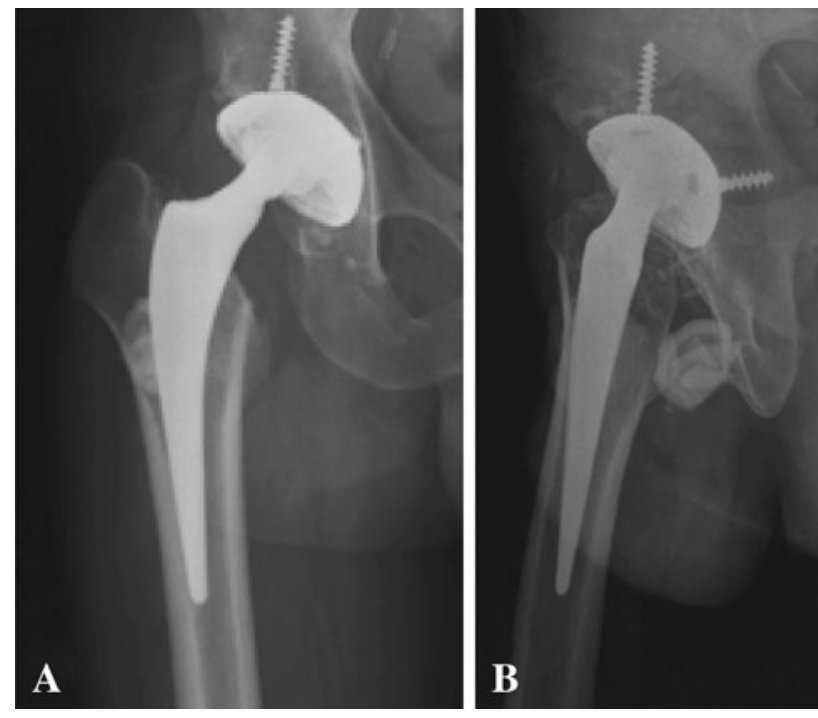

Fig. 1A-B (A) AP and (B) lateral view radiographs show the prosthesis with fracture of the right ceramic sandwich liner.
THAs for osteonecrosis of the femoral head, one patient had THA for hip dysplasia, one had THA for synovial osteochondromatosis, one had THA for primary osteoarthritis, and one had THA for infected nonunion after a femoral neck fracture. Three of the seven patients had a history of hip surgery. A posterolateral surgical approach was used in these seven patients. The mean size of the acetabular cup was $54.7 \mathrm{~mm}$ (range, 52-58 $\mathrm{mm}$ ). The ceramic head was always of medium neck length. The femoral stems were not cemented in six cases. Five patients had no complications after primary surgery and the early followup was uneventful. One patient had a wound infection with subsequent débridement. None of the seven patients sustained a postoperative dislocation. None of the seven had a history of trauma related to the ceramic fracture. All failures occurred during daily activity when the hip was in hyperflexion (eg, squatting, rising from a chair, putting on boots). Symptoms of liner fracture included audible crepitation, pain, and loss of motion (Table 2). Like the symptoms listed, observations at the time of reoperation for the fracture group were varied and included metallosis; wear of the polyethylene (probably secondary to ceramic fracture/debris production), the femoral head, or of the neck component; and tiny ceramic particles embedded in the inner surface of the polyethylene (Fig. 2). The ceramic layer was always detached from the polyethylene and was fractured into four variable-sized small fragments (Fig. 3). The reoperation consisted of changing the bearing surface in all cases, the acetabular cup in one case, the femoral stem in one case, and both components in one case. Extensive synovectomy was performed in all cases.

At last followup the pain score had improved from 2.1 to 5.7 (range, 2-6), walking had improved from 4.1 to 5.8 (range, 2-6), and mobility had improved from 5.1 to 5.9 (range, 4-6). The Merle d'Aubigné-Postel score [6] increased from 10.9 to 17.5 . Despite the high mean function, 34 patients $(10 \%)$ had an activity level classified as 2 according to the score of Devane et al. [7].

Table 2. Data for the seven ceramic liner fractures

\begin{tabular}{|c|c|c|c|c|c|}
\hline $\begin{array}{l}\text { Patient } \\
\text { number }\end{array}$ & $\begin{array}{l}\text { Time in } \\
\text { situ (years) }\end{array}$ & $\begin{array}{l}\text { Activity at the } \\
\text { time of fracture }\end{array}$ & Clinical symptoms & $\begin{array}{l}\text { Time of } \\
\text { diagnosis }\end{array}$ & $\begin{array}{l}\text { Noise before } \\
\text { fracture }\end{array}$ \\
\hline 1 & 7.6 & Dislocating movement & Pain, functional disability & Few days & No \\
\hline 2 & 4.3 & Getting up from a chair & Crepitation, loss of motion & 1 month & No \\
\hline 3 & 3.3 & Squatting & Blocking & 6 months & No \\
\hline 4 & 3.8 & Threading boots & $\begin{array}{l}\text { Pain, functional disability, } \\
\text { crepitation }\end{array}$ & Few days & $\begin{array}{l}\text { Yes ( } 3 \text { days } \\
\text { before) }\end{array}$ \\
\hline 5 & 1.3 & Not found & None & Not found & Not found \\
\hline 6 & 5.3 & Squatting & Functional disability & Few days & No \\
\hline 7 & 4.6 & Squatting & Pain & Few days & No \\
\hline
\end{tabular}


Fig. 2A-C (A) Wear of the prosthesis head, (B) metallosis of the tissue and fracture of the ceramic liner, and (C) embedded ceramic fragments in polyethylene can be seen in these photographs.
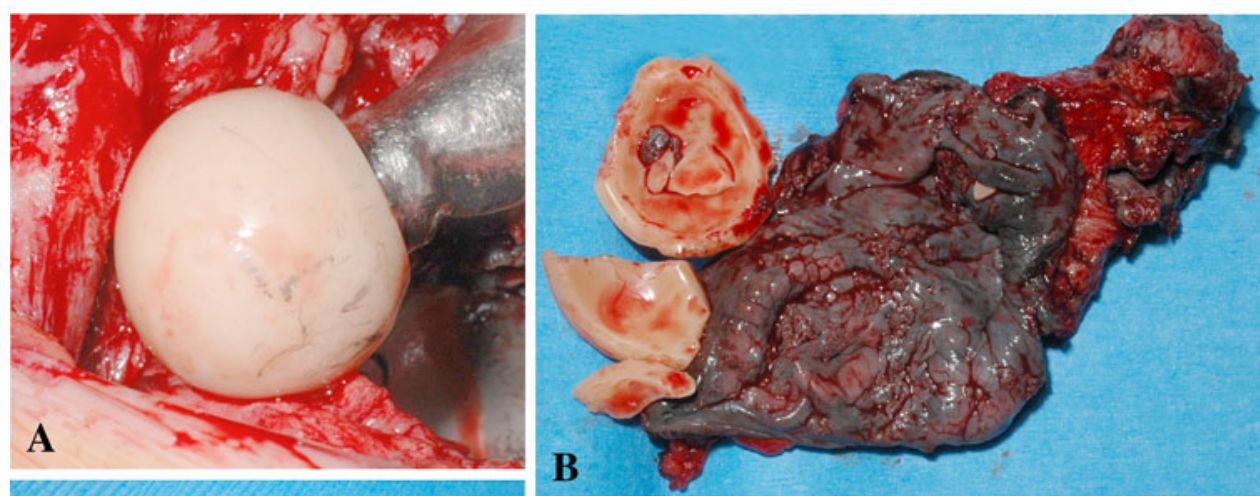

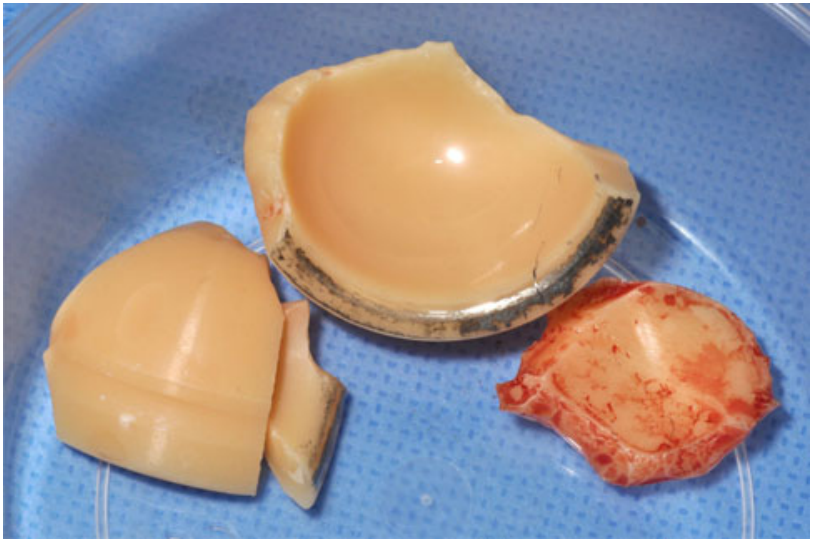

Fig. 3 A ceramic liner fracture is shown in this photograph.

Both groups were similar in terms of age, gender, BMI, acetabular cup position, or characteristics of the femoral stem. The average abduction angle of the acetabular cup was $43.1^{\circ}$ (range, $39^{\circ}-49^{\circ}$ ) for these seven patients compared with $45.5^{\circ}$ for the whole series (Table 3 ).

\section{Discussion}

Based on a reported high survival rate $(100 \%$ at 11 years [11]) of ceramic-ceramic bearing surfaces, we opted to use
Table 3. Comparison of predisposing factors for fracture and nonfracture groups

\begin{tabular}{llll}
\hline $\begin{array}{l}\text { Predisposing } \\
\text { factor }\end{array}$ & $\begin{array}{l}\text { Fracture } \\
\text { group }\end{array}$ & $\begin{array}{l}\text { Nonfracture } \\
\text { group }\end{array}$ & $\begin{array}{l}\text { Statistical } \\
\text { meaning }\end{array}$ \\
\hline $\begin{array}{l}\text { Weight }(\mathrm{kg}) \\
\text { Mean }\end{array}$ & 75.8 & 76.2 & NS \\
Range & $(56-125)$ & $(40-127)$ & \\
SD & 23.66 & 15.5 & NS \\
BMI $\left(\mathrm{kg} / \mathrm{m}^{2}\right)$ & & & \\
Mean & 24.5 & 26.5 & \\
Range & $(20-38.6)$ & $(17.2-42.6)$ & \\
SD & 6.9 & 4.5 & \\
$\begin{array}{l}\text { Devane et al. [7] score } \\
\text { activity distribution }\end{array}$ & & & \\
Level 1 & $0(0 \%)$ & $0(0 \%)$ & \\
Level 2 & $1(14 \%)$ & $33(12.7 \%)$ & \\
Level 3 & $3(43 \%)$ & $91(35 \%)$ & \\
Level 4 & $2(29 \%)$ & $77(29.6 \%)$ & \\
Level 5 & $1(14 \%)$ & $59(22.7 \%)$ & \\
Acetabular & & & NS \\
$\quad$ cup abduction $\left(^{\circ}\right)$ & & & \\
Mean & 43.1 & 45.5 & \\
Range & $(39-49)$ & $(15-75)$ & \\
SD & 4.1 & 9.3 & \\
\hline
\end{tabular}

NS = not significant 
a ceramic sandwich liner. Our observation of fractures at relatively short followup led us to evaluate the prevalence of this complication.

There are limitations to our study. First, it is a singlecenter study. Although such a study reduces potentially confounding variables such as patient selection and surgeon experience, it might make the findings less generalizable. Second, the mean followup is relatively short (41 months), whereas the mean time to fracture was 51 months. Therefore, additional fractures might occur after our followup times. However, we had less than $2 \%$ of patients lost to followup and would not have missed many fractures during followups. Third, the incidence of fracture might be understated, as the polyethylene sandwich might delay recognition of liner failure by the patient. However, we presume all fractures were detected in our patients. Our study was limited by the small number of events (fractures) and therefore has low statistical power; however, despite the retrospective design and short followup, we found an abnormally high rate of fractured sandwich ceramic liners (2\%). Because of the small number of events (eg, fracture of the ceramic liner), we were unable to explore factors relating to the fractures.

This observational study confirms the relatively high rate of ceramic bearing surface failure reported in the literature $[8,12,15]$ (Table 4). No trauma or abnormal physical activity was observed in our patients.

Some authors $[12,15]$ report that some positions have greater risk, eg, squatting or sitting in a cross-legged position. These positions were not reported by our patients; instead, five patients described being in a hyperflexed position at the time of the fracture. Unlike Popescu et al. [16] and Poggie et al. [15], the mean BMI for patients in our fracture group was $24.5 \mathrm{~kg} / \mathrm{m}^{2}$, and only one patient was severely obese at the time of fracture. Surgical technique can be problematic, and an incorrect acetabular implant position has been suggested as a cause [9, 12]. Popescu et al. [16] found excessive retroversion in one patient, whereas Ha et al. [8] observed a mean anteversion of $25.8^{\circ}$ in their fracture group, which was greater than the $16.1^{\circ}$-angle in their nonfracture group. Although we did not estimate version of the acetabular cup, the high rate of dislocation in our series could suggest inadequate position of the cup on a horizontal plane despite good position on the coronal plane in most cases (range, $39^{\circ}-49^{\circ}$ ). Nevertheless, no dislocations occurred before the diagnosis of a liner fracture. We could not relate acetabular position and liner fracture on the basis of our limited study. The high dislocation rate can be explained by various predisposing factors (posterolateral approach, osteonecrosis, dysplasia, revision surgery for diagnosis, and high rate of previous surgery on the ipsilateral hip). Two other specifications of the implant have been suspected to be problematic: the

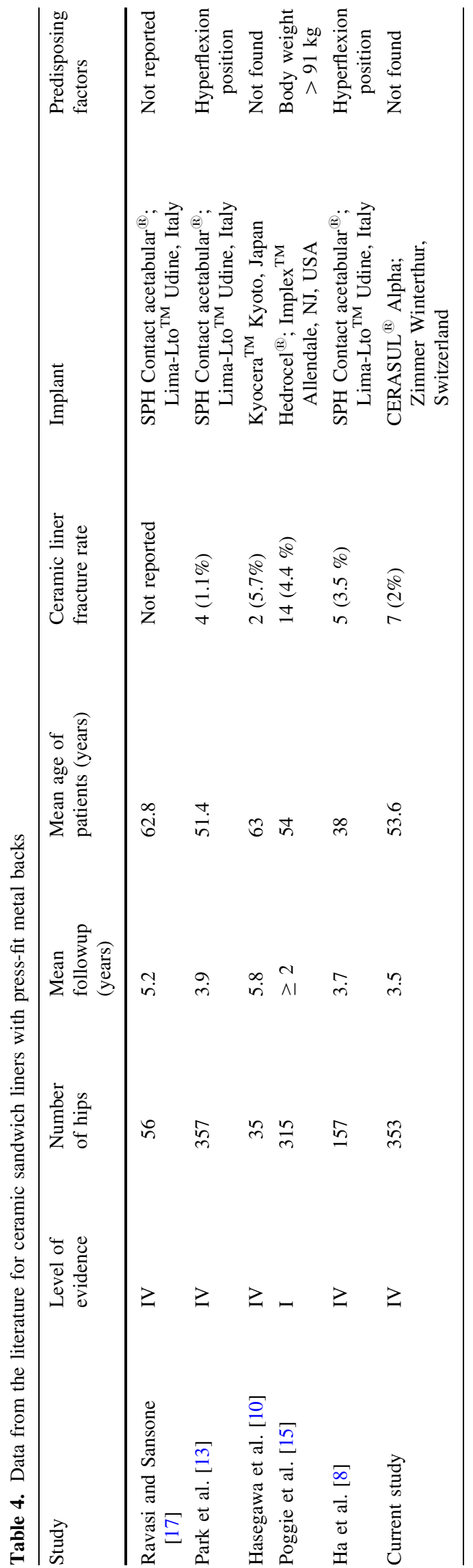


thermocompressive system for combining the ceramic and polyethylene layers and the characteristics of the polyethylene used.

Several explanations have been offered to explain ceramic liner fractures. Some investigators [15] suggest a simple association between the hydrophobic polyethylene and the absorbent ceramic lead to fracture; others [8] suspect the high torque transmitted from the femoral head to the ceramic liner. Hasegawa et al. [9] believed the loading edge was responsible. All these authors believe these different situations can dislodge the ceramic liner and cause a secondary fracture. Park et al. [12] believes impingement is directly responsible for the ceramic sandwich fracture. Like Benazzo [2], we believe a combination of events could lead to a fracture. The role of edge loading is possible, and impingement could act as a recurrent mechanical stress and/or could allow clinical expression by displacing the fractured fragment of ceramic. The mechanism of liner fracture is debatable $[8,10,12,15,16]$.

We have discontinued implantation of the ceramic sandwich liner because of the high rate of fracture (2\%) at short-term followup.

\section{References}

1. Barrack RL, Burak C, Skinner HB. Concerns about ceramics in THA. Clin Orthop Relat Res. 2004;429:73-79.

2. Benazzo FM. Failure mechanisms of ceramic total hip arthroplasty. (Comment on J Bone Joint Surg Am. 2006;88:780787.) J Bone Joint Surg Am. 2007;89:1131-1132; author reply 1132-1133.

3. Boutin P. [Alumina and its use in surgery of the hip. (Experimental study)] [in French]. Presse Med. 1971;79:639-640.

4. Boutin P. [Total arthroplasty of the hip by fritted aluminum prosthesis: experimental study and 1st clinical applications] [in French]. Rev Chir Orthop Reparatrice Appar Mot. 1972;58:229-246.
5. Charnley J. The long-term results of low-friction arthroplasty of the hip performed as a primary intervention. J Bone Joint Surg Br. 1972;54:61-76.

6. D'Aubigne RM, Postel M. Function al results of hip arthroplasty with acrylic prosthesis. J Bone Joint Surg Am. 1954;36:451-475.

7. Devane PA, Horne JG, Martin K, Coldham G, Krause B. Threedimensional polyethylene wear of a press-fit titanium prosthesis: factors influencing generation of polyethylene debris. J Arthroplasty. 1997;12:256-266.

8. Ha YC, Koo KH, Jeong ST, Joon Yoo J, Kim YM, Joong Kim H. Cementless alumina-on-alumina total hip arthroplasty in patients younger than 50 years: a 5-year minimum follow-up study. J Arthroplasty. 2007;22:184-188.

9. Hasegawa M, Sudo A, Hirata H, Uchida A. Ceramic acetabular liner fracture in total hip arthroplasty with a ceramic sandwich cup. $J$ Arthroplasty. 2003;18:658-661.

10. Hasegawa M, Sudo A, Uchida A. Alumina ceramic-on-ceramic total hip replacement with a layered acetabular component. J Bone Joint Surg Br. 2006;88:877-882.

11. Kim YH, Choi Y, Kim JS. Cementless total hip arthroplasty with ceramic-on-ceramic bearing in patients younger than 45 years with femoral-head osteonecrosis. Int Orthop. 2010;34:11231127.

12. Park YS, Hwang SK, Choy WS, Kim YS, Moon YW, Lim SJ. Ceramic failure after total hip arthroplasty with an alumina-onalumina bearing. J Bone Joint Surg Am. 2006;88:780-787.

13. Park YS, Park SJ, Lim SJ. Ten-year results after cementless THA with a sandwich-type alumina ceramic bearing. Orthopedics. 2010;33:796.

14. Petsatodis GE, Papadopoulos PP, Papavasiliou KA, Hatzokos IG, Agathangelidis FG, Christodoulou AG. Primary cementless total hip arthroplasty with an alumina ceramic-on-ceramic bearing: results after a minimum of twenty years of follow-up. $J$ Bone Joint Surg Am. 2010;92:639-644.

15. Poggie RA, Turgeon TR, Coutts RD. Failure analysis of a ceramic bearing acetabular component. J Bone Joint Surg Am. 2007; 89:367-375.

16. Popescu D, Gallart X, Garcia S, Bori G, Tomas X, Riba J. Fracture of a ceramic liner in a total hip arthroplasty with a sandwich cup. Arch Orthop Trauma Surg. 2008;128:783-785.

17. Ravasi F, Sansone V. Five-year follow-up with a ceramic sandwich cup in total hip replacement. Arch Orthop Trauma Surg. 2002;122:350-353. 